\title{
I Will Follow Him: The Value of Human Brands' Social Media Power for New Product Success
}

\author{
Ann-Kristin Knapp, Nora Paehler vor der Holte, \\ and Thorsten Hennig-Thurau
}

\begin{abstract}
Contradicting anecdotes can be found on the question of whether or not having millions of followers on Twitter and Facebook offers a competitive advantage when it comes to selling products. Also, regarding academic research on this matter, we find that little is known about the incremental effect of social media activities. This is especially noteworthy as marketing managers in several industries are investing heavily to harvest the social media power of so-called human brands. These human brands such as Vin Diesel, Cara Delevingne, or Christina Aguilera are prominently used in an entertainment media context but also to sell, for example, clothes and perfumes.

This research investigates whether employing human brands with many followers on social media provides an incremental economic value for launching new products. To address this question, we collected proprietary data from the movie industry. Using this data, we determine the monetary value of a social media fan base when it comes to selling new products. We furthermore identify contingency factors that increase or decrease the potential influence of a human brand's social media power on new product success.
\end{abstract}

\footnotetext{
A.-K. Knapp $(\bowtie) \bullet$ N.P. vor der Holte • T. Hennig-Thurau

University of Muenster, Münster, Germany

e-mail: Ann-Kristin.Knapp@wiwi.uni-muenster.de; Nora.PaehlervorderHolte@wiwi.

uni-muenster.de; Thorsten@Hennig-Thurau.de
} 